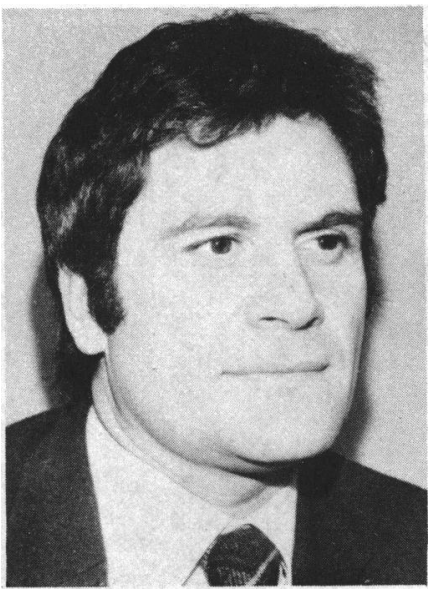

ASSOCIATED FACTORS IN RECURRENT GROIN AND HAMSTRING INJURIES

\author{
D. S. MUCKLE, MS, MD, FRCS
}

Consultant Orthopaedic Surgeon, Middlesbrough; Medical Adviser FIFA

\section{S. Muck/e}

Recurrent groin and hamstring injuries are amongst the most difficult and refractory problems in sports medicine. Although accounting for only $14 \%$ of all sports injuries the amount of playing time lost is disproportionately high; thus, in one soccer season they were responsible for almost thirty per cent of missed matchunits (Muckle, 1982).

The majority $(85 \%)$ of groin and hamstring problems begin with an acute episode (Fig. 1) but because of inadequate treatment or faulty technique they become recurrent. Therefore, they are preventable. On the other hand, there are often additional factors which may mimic or obscure the clinical picture in a refractory $15 \%$ of cases. The aim of this article is to highlight those extra factors which must be considered in diagnosis before a rational therapeutic approach can be made.

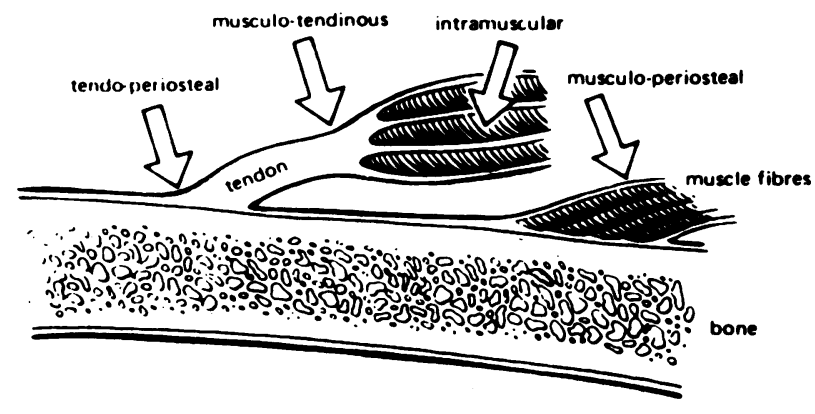

Fig. 1: Indirect muscle injuries occur at the sites shown (Muckle, 1982).

\section{Recurrent Groin Strain}

This condition is commonly found in hockey and soccer players with $6 \%$ of the latter suffering one acute episode per season (Jankovic, 1977). The principal tendons affected are the pelvic attachments of the adductor longus, rectus femoris, sartorius and ilio-psoas. However, recurrent strain chiefly affects the adductor longus tendon at the tendo-periosteal or musculo-tendinous junctions.

\section{a. Osteitis Pubis}

All patients with recurrent groin discomfort must have a pelvic $X$-ray at monthly intervals while under treatment (Fig. 2). Since the blood supply to the pubic bones arises mainly from an "end-artery" arrangement, recurrent microtrauma can cause thrombosis and aseptic necrosis of the bone and cartilage (Adams and Chandler, 1953). Radiological changes have been described in $26 \%$ of players with recurrent groin paid (Eissmann, 1972). Sport should cease for 3-6 months and this condition will remit spontaneously.

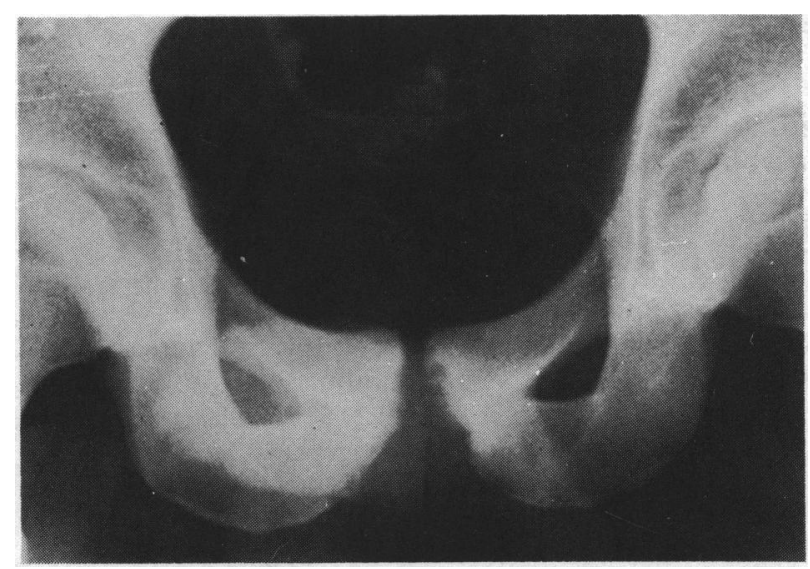

Fig. 2: Osteitis pubis in a young, international soccer player treated for recurrent groin strain for 3 months. 


\section{b. Spinal Abnormalities}

Evidence of old osteochondritis of the vertebral bodies (Scheuermann's disease), a disc lesion at $L_{1}$ or $L_{2}$ and a crush fracture at either of these levels, can cause radicular pain that imitates groin strain. An $X$-ray of the thoraco-lumbar junction concludes the diagnosis and the appropriate therapy is given. Strangely, lower spinal problems may also be implicated. Boeda (1973) investigated 16 athletes (11 footballers, 2 rugby players and 3 marathon runners) with recurrent groin problems and detected lower lumbar and sacral abnormalities which were responsible for excessive pelvic tilt and secondary groin stress.

\section{c. Hip Abnormalities}

Junge (1964) studied the pelvic X-rays of 950 sportsmen and found that hip problems such as minor subluxation of the femoral head were frequently associated with groin pain and a symphysis pubis lesion.

\section{d. Other Lower Limb Problems}

Faulty running techniques due to the "short-leg syndrome", pronated feet and tibial torsion (with an unequal stride length) may cause abnormal unilateral stresses in the groin, with the adductors attempting to balance excessive abduction power at the hip. Such faults are accentuated by incorrect running shoes and uneven surfaces. Correct attention to style, equipment and training conditions are needed under these circumstances.

\section{e. Enthesopathic Component of Inflammatory Rheu- matic Disease}

In chronic cases the various causes of enthesopathies such as gout, ankylosing spondylitis, Reiter's syndrome and other sero-negative spondarthritides (Niepel and Sitaj, 1979) should be investigated.

Surgical conditions such as hernias and genito-urinary problems (including posterior urethritis and prostatitis) must be excluded.

\section{Recurrent Hamstring Injuries}

\section{a. Lumbar Spine Abnormalities}

Spasm of the hamstrings limiting hip and lumbar mobility can be present with a lumbo-sacral problem such as a mild disc at $L_{4} / L_{5}$ or $L_{5} / S_{1}$ levels, facet joint arthrosis or with a spondylolysis (Fig. 3). The missed association between lumbar spinal problems and recurrent hamstring injuries is a common cause of inadequate therapy. If there is any suggestion of hamstring tightness as detected by an estimation of lumbar flexion then spinal mobility exercises (with pool therapy) must be undertaken.

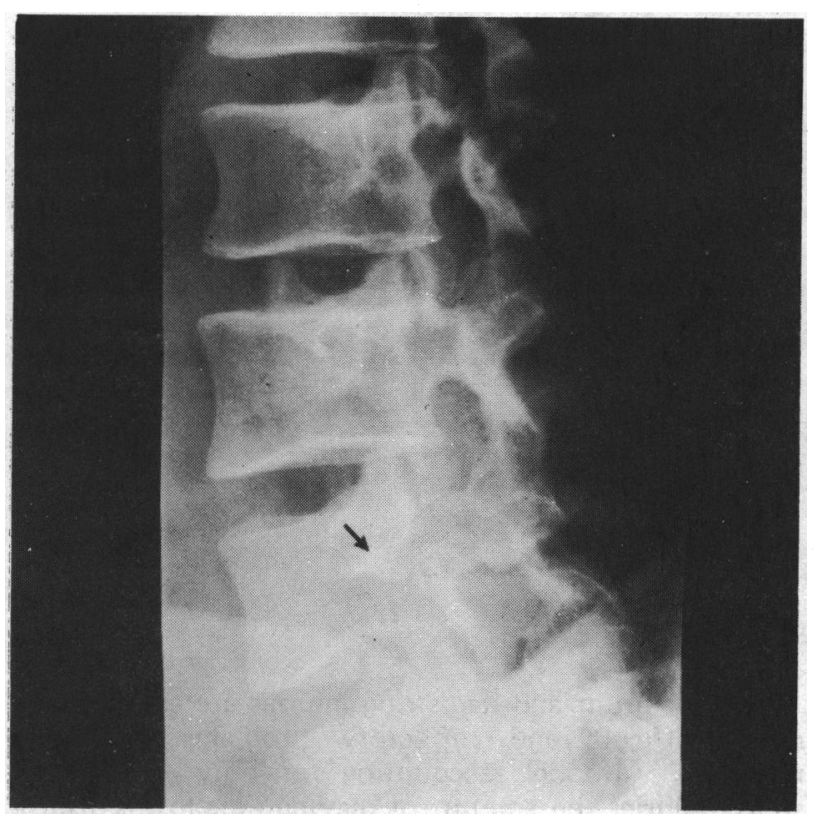

Fig. 3: Spondylolysis in a runner with tight hamstrings and recurrent tearing.

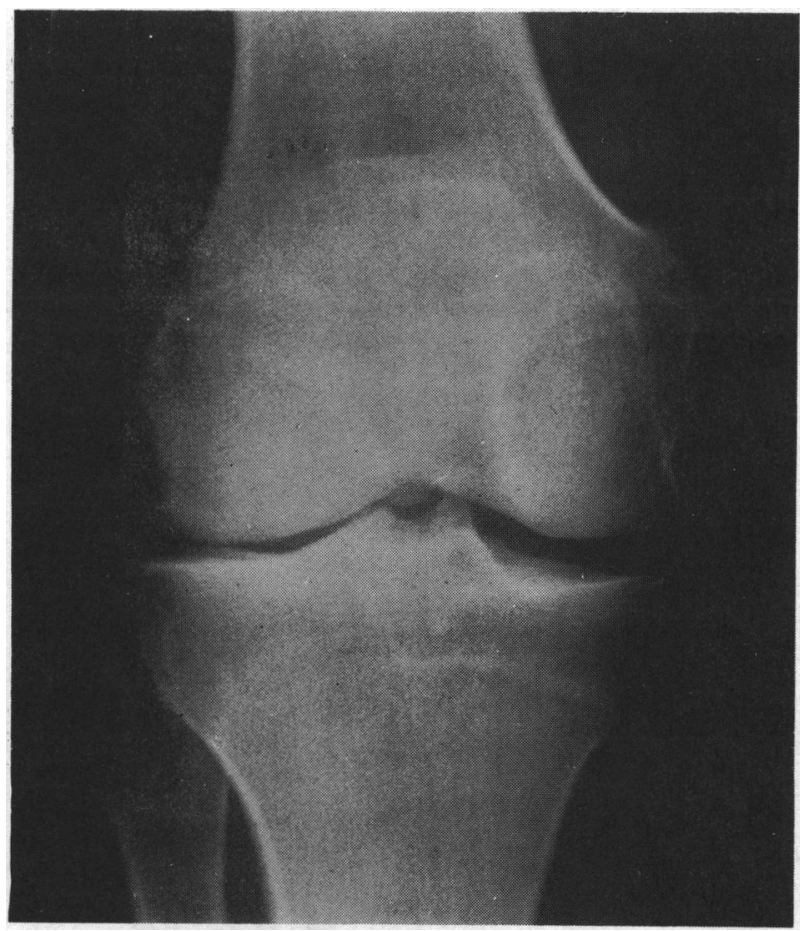

Fig. 4: Marked osteoarthrosis due to lateral meniscectomy 6 years earlier. Player subjected to recurrent hamstring pulling in the biceps femoris due to lateral rotatory instability. 


\section{b. Meniscal Problems in the Knee}

The hamstrings act as dynamic stabilisers of the knee (Hsieh and Walker, 1976) and consequently incomplete knee excursion from meniscal tears, degeneration or excision can lead to excessive loading on the hamstrings (especially biceps femoris which is inserted into the lateral compartment (Nicholas, 1973)) (Fig. 4). Also minor degrees of rotatory instability (Muckle, 1982) can be implicated. The correction to full knee movements by physiotherapy, meniscectomy or ligament reconstruction is required.

\section{c. Adhesion of the Lateral Popliteal Nerve}

A tear in the lower muscle belly of biceps femoris with subsequent fibrosis and intermuscular adhesions may trap the intimately situated lateral popliteal nerve causing recurrent painful episodes especially sprinting and hurdling. Treatment is by freeing the nerve from the adhesions, usually indicated by the point of maximum tenderness.

\section{d. Abnormal Quadriceps Power}

An unbalanced quadriceps action due to excessive muscle hypertrophy, commonly seen in footballers, may produce an abnormal force in the hamstrings when there is loss of co-ordination due to fatigue. Exercises should be instituted to correct the imbalance.

e. Enthesopathies (as outlined under groin strain)

In conclusion it can be stated that the majority of recurrent groin and hamstring problems have a basis within the muscle complex (i.e. primary cause) but in approximately $15 \%$ of cases associated factors are involved, the recurrent injury being a secondary problem which will not remit unless therapy is directed towards the initiating factors.

\section{REFERENCES}

Adams, R. J. and Chandler, F. A., 1953 "Osteitis pubis of traumatic aetiology". J.Bone Joint Surg. 35A: 658.

Boeda, A., 1973 "Á propos de la maladie des adducteurs". Med.du Sport (Paris) 47: 127.

Eissmann, H. J., 1972 "Zur aetiologie, symptomatologie, differentialdiagnose, therapie, und prophylaxes des "leistenschmerzes" bein jugendlichen fussballspielern". Med.u Sport (Berlin) 12: 80.

Hsieh, H. H. and Walker, P. S., 1976 "Stabilising mechanisms of the loaded and unloaded knee joint". J.Bone Joint Surg. 58A: 87.

Jankovic, G., 1977 "Prevention of pubic pain in football players". SMO-SMJ 14: 623.

Junge, H., 1964 "Recherches sur le resultat des forces considerables agissant sur la ceinture pelvienne anterieure chez les sportifs". Proc.XV Int.Congr.Sport Sciences, Tokyo, p. 372.

Muckle, D. S., 1982 "Ligamentous injuries in the knee". Injuries in Sport, 2nd Edition, p. 68. Bristol, Wright.

Nicholas, J. A., 1973 "The five-one reconstruction for anteromedial instability of the knee". J.Bone Joint Surg. 55A: 899.

Niepel, G. A., and Sitaj, S., 1979 "Enthesopathy". Clinics in Rheum.Dis. 5: 857. 